\title{
The Estimated Prevalence of Autism in School-Aged Children Living in Rural Nepal Using a Population-Based Screening Tool
}

\author{
Michelle Heys ${ }^{1,2}$ - Felicity Gibbons ${ }^{3} \cdot$ Ed Haworth $^{2} \cdot$ Emilie Medeiros $^{1} \cdot$ Kirti Man Tumbahangphe $^{4}$. \\ Mary Wickenden ${ }^{1} \cdot$ Merina Shrestha ${ }^{5,6} \cdot$ Anthony Costello $^{1,7} \cdot$ Dharma Manandhar $^{4} \cdot$ Elizabeth Pellicano $^{8,9}$
}

Published online: 31 May 2018

(c) The Author(s) 2018

\begin{abstract}
Few data exist on the prevalence of autism in low-income countries. We translated, adapted and tested the acceptability of a Nepali-language version of a screening tool for autism (Autism Quotient-10). Using this tool, we estimated autism prevalence in 4098 rural Nepali children aged 9-13 years. Fourteen children scored $>6$ out of 10, indicative of elevated autistic symptomatology, of which 13 also screened positive for disability. If the AQ-10 screening tool is as sensitive and specific in the Nepali population as it is in the UK, this would yield an estimated true prevalence of 3 in 1000 (95\% confidence interval 2-5 in 1000). Future research is required to validate this tool through in-depth assessments of high-scoring children.
\end{abstract}

Keywords Autism $\cdot$ Prevalence $\cdot$ Screening

\section{Introduction}

Autism is a global phenomenon. An estimated $1-2 \%$ of children worldwide lie on the autism spectrum, with approximately 52 million autistic ${ }^{1}$ individuals across the globe (Baxter et al. 2015). These estimates are largely driven, however, by prevalence estimates from high-income countries (HIC). Virtually no data exist on the population prevalence of autism in low-income countries (LIC) and only one in a LIC rural setting (Uganda: Kakooza-Mwesige et al. 2014). In fact, there is a paucity of research examining autism generally in these regions at all (Abubakar et al. 2016). Studies that have been conducted in lower-middle and upper-middle income countries have produced varied results reporting prevalence estimates ranging from 0.32 (China: Tao 1987) to 250 per 10,000 (China: Ren et al. 2003) and more recently

A version of a subsection of this paper was presented in poster format at the Royal College of Paediatrics and child health annual conference 2016.

Electronic supplementary material The online version of this article (https://doi.org/10.1007/s10803-018-3610-1) contains supplementary material, which is available to authorized users.

Michelle Heys

m.heys@ucl.ac.uk

Extended author information available on the last page of the article
90 per 10,000 (India: Raina et al. 2017). These discrepancies are possibly due to a variety of reasons, including the fact that autism is a spectrum condition (American Psychiatric Association 2013), the variety of traits; changing definitions of autism; varying levels of awareness in different countries; cultural variation in expectations and understandings of children's behavior; different methodological approaches used to assess prevalence; and the lack of availability of culturally-sensitive diagnostic tools and year of assessment (Elsabbagh et al. 2012).

Variation in methodological approaches to assessing autism prevalence includes differences in case-finding techniques, from population-based sampling (Baird et al. 2006) to sampling from clinics and healthcare registers (Croen et al. 2002). Variation is also found in the method of diagnosing or screening cases for autism, including a mix of relying on healthcare or educational reports (Idring et al. 2012) and/or researchers assessing for autism first-hand using comprehensive diagnostic tools including the Autism Diagnostic Observation Schedule (ADOS) and the Autism Diagnostic Interview (ADI) (Kim et al. 2011), to less sensitive screening tools or questionnaires, based on different

\footnotetext{
${ }^{1}$ Identity-first language (i.e. autistic person), opposed to personfirst language (i.e., person with autism), is preferred by many autistic people and their allies (see Kenny et al. 2016) and (Sinclair 1999). Therefore, in this article, the authors use predominantly identity-first language.
} 
standards and diagnostic criteria (Stewart and Lee 2017). Furthermore, while many studies have investigated the prevalence of autism in Western societies, the general consensus is that there is an urgent need for more studies investigating the prevalence of autism in LICs (Abubakar et al. 2016; Elsabbagh et al. 2012; Mpaka et al. 2016; Ruparelia et al. 2016), in particular LIC rural settings using low-cost, community-based screening tools that can be administered by lower cadres of health workers. Without these tools and studies, it is impossible to draw an accurate prediction of the global prevalence of autism and develop appropriate services that can cater for the needs of autistic children and adults and their families.

Sixty-one percent of the world's population of children and young people live in LICs or lower- to middle-income countries (LMIC). Nepal is one of the poorest LICs (World Bank 2016) and one of only four LICs outside of sub-Saharan Africa. The majority (estimated 82\%) of its population lives rurally (World Bank 2014). Nepal has a growing population of about 26.7 million people due to high birth rate and declining death rate. The Autism Care Nepal Society website states that there is "no reliable estimate for the prevalence of autism in Nepal as autism is not known to many people" (Autism Care Society Nepal). Indeed, recent qualitative evidence from this population shows limited understanding of many aspects of atypical child development, in particular autism - but a strong desire to advocate for and increase support for these children and their families (Heys et al. 2016).

The overarching aim of the current study was to establish the prevalence of autism in school-aged children living in Nepal. In a preliminary screening-adaptation and acceptability study, we first sought to identify a low cost, short, population-based screening tool with good sensitivity and specificity that could potentially be delivered by all cadres of health care workers to detect possible autism in children and young people in a rural Nepali setting. We then sought to develop a Nepali-language adaptation of the identified screening tool, the AQ-10 (Allison et al. 2012), which would be acceptable for Nepali parents.

In the prevalence study, we used the resulting tool to estimate the prevalence of autism in 9-13 year-old Nepali children living in Makwanpur District, a rural hill area in the central region in which most households are dependent on subsistence agriculture (population $>500,000$ in 2014). We also assessed the validity of the adapted AQ-10 within the same population by comparing results of a screening tool for childhood disability, which included questions on social and communication skills, and was delivered 6 months previously to the same cohort of children.

Our research aims were twofold: (1) to examine whether the AQ-10 is acceptable for use with Nepali parents and (2) to determine the estimated prevalence of autism in a rural population of Nepali children using the adapted AQ-10.

\section{Method}

\section{Study Overview}

Here, we describe two interrelated studies. The first study was designed to assess the adaptation and acceptability of a population-based screening tool. The second was a population-based prevalence study using the adapted screening tool. Data collection for the prevalence study occurred in two waves, wave 1 from Jan 2014 to July 2014 (during which a wide range of demographic and clinical data were obtained, including disability prevalence) and wave 2 from Sept 2014 to Jan 2015 (during which the autism screening was conducted). Description of sample size, inclusion and exclusion criteria and variables of interest are outlined in the two study sections.

\section{Preliminary Screening Tool Adaptation and Acceptability Study}

There were three stages to this adaptation study: (1) the identification of the best fit screening tool, (2) translation and back translation of the chosen tool, and (3) a qualitative study on its acceptability.

\section{Identification of Screening Tool}

To begin, we conducted a review of available literature on population-based screening tools for autism using the search terms, 'autis*', 'ASD' and 'screening' in PubMed and the reference lists of existing articles. The key characteristics of these tools, including length of administration, cost, population target, evidence base, specificity and sensitivity and reporter characteristics (e.g., parent versus clinician report), were identified. Our criteria for tool selection for the current study included: (1) being population based, (2) for use across childhood and adolescence; (3) being freely available; (4) being short in length of administration; (5) requiring parent report only; and (6) having demonstrated sufficiently high sensitivity and specificity. Supplementary Table 1 shows the 12 screening tools that were identified, of which only one (the AQ-10; Allison et al. 2012) fitted best our criteria.

\section{Adaptation and Translation of the Screening Tool}

The Autism Quotient-10 (AQ-10; Allison et al. 2012) was identified in the review of screening tools as the most feasible for use in this population-based study, where the tool would be administered by trained Nepali field research assistants. It is a short version of the AQ-50, which was originally developed as a tool for screening for autistic traits in intellectually able adults (Baron-Cohen et al. 2001). A cut-off 
score of 6 or more out of 10 is used to identify children and young people who have a likely diagnosis of autism, with excellent sensitivity (93\%) and specificity (97\%) in UK populations (Allison et al. 2012). It has a child, adolescent and adult version, requires only limited specific knowledge of ASD, is administered in a short amount of time and is freely available.

Next, we translated (and back-translated) the AQ-10 in discussion with UK and Nepali pediatricians and clinical psychologists in line with the gold standard WHO guidance on adaptation of English language tools (World Health Organization 2013). All of the team involved in the translation were bilingual Nepali/English except for one (UK pediatrician). In Nepal, we discussed the translation with a small group of European and Nepali researchers, pediatricians and clinical psychologists. Team members' experience of autism varied widely from those for which a major part of that person's role related to diagnosis and management of autistic children and young people (e.g., Nepali clinical psychologist, pediatrician) to those who had little to no experience of working with autism (Nepali researchers). We reviewed the cultural equivalence of each item and underlying concepts in light of the Nepalese constructions of childhood, maturity and the ethnopsychological concepts of the mind (Kohrt and Harper 2008; Medeiros 2014). This allowed us to elicit the most appropriate experiential equivalent in the Nepali language.

\section{Acceptability Study}

The final, qualitative arm of the adaptation study was conducted in both rural (Makwanpur) and urban (Kathmandu) Nepal in the spring of 2014 as part of a larger qualitative study exploring Nepali parents and professionals' understanding of typical and atypical child development (Heys et al. 2016). The translated version was tested for acceptability in three focus groups of parents $(n=28 ; 10 \mathrm{Kathmandu-}$ based mothers, fathers and/or carers with a child with a known diagnosis of autism and 18 rural mothers, fathers and carers from lower caste and ethnic groups [janajatis] with a child(ren) without a known diagnosis of autism).

The main outcome of interest for this qualitative arm was the acceptability of the AQ-10 for use as a screening tool. The Kathmandu-based participants were purposefully recruited by our collaborators Autism Care Nepal Society (ACSN) with the inclusion criteria being: parent and/or main carer of a child (aged up to 18 years) with a known diagnosis of autism (confirmed by the clinical team at ACSN from their records). There were no exclusion criteria. These parents were mostly from a high caste, middle class and educated background living in the capital, Kathmandu. The Nepali caste system is a method of social stratification practiced by most but not all ethnic groups in Nepal.
The Makwanpur-based parents were recruited in collaboration with our partners Mother and Infant Research Activities (MIRA). The inclusion criteria were parent/carer and/ or grandparent of a typical child of any age. The exclusion criterion was any known diagnosis of atypical child development (including autism). Participant characteristics for these focus groups are shown in Table 1.

The same research team adapted the content and the approach used in the focus groups to ensure cultural validity. We also ensured that the content discussed was accessible for the participants who had lower literacy levels, by simplifying the language, and limiting reference to abstract concepts. The approach used in the delivery of the focus group was also tailored to address the power imbalance between some of the participants (rural uneducated women) and the representations of the researchers (high caste, some male, educated middle class from the capital, Kathmandu) - by ensuring the lead facilitators were female and of a lower caste. A fourth additional workshop was held with parents of autistic children to help clarify any uncertainties around Nepali language terms for atypical child behaviors as autistic symptomatology is common among children with atypical child development.

In the initial focus groups, each of the ten questions in the AQ-10 were considered in turn, participants were asked to discuss each statement/question and consider whether each statement/question described usual or unusual child behaviors. We used the translated version of the tool with both groups of parents for consistency as this was the version we were intending to use in the prevalence study. This procedure was essential for understanding whether the final translated version (not previous untranslated/original versions) was acceptable. All participants were asked how they felt about discussing the questions and whether other parents (of children with or without a known diagnosis of autism) would be willing and able to answer the questions about their child. This discussion was facilitated using prompts such as "Do you think these questions are easy or difficult to answer?" and "Do you think parents will mind answering these questions about their children?". Each item was discussed until there was consensus from focus group participants that the items would be acceptable for completion by Nepali parents. All participants consented for the focus group discussions to be recorded.

\section{Analysis of Qualitative Data}

Interview recordings were transcribed verbatim and subjected to thematic analysis following Braun and Clarke (2006) through NVivo10 (QSR International Pty Ltd 2012) as well as manually by three of the authors. The analytic process was iterative and inductive in nature. The authors independently familiarized themselves with the data and met 
regularly to discuss preliminary themes and codes, resolve discrepancies and decide on the final themes and subthemes.

\section{Prevalence Study}

\section{Prevalence Study Design and Timeframe}

The prevalence study was a cross-sectional study of 4098 children from Makwanpur district, rural Nepal conducted between Jan 2014 and Jan 2015 in two waves of interviews and data collection. Each wave of data collection item was preceded by a pilot of data collection procedures. These 4098 children were recruited within the broader context of a long-term follow-up study (Heys et al. 2016) of a cluster randomized controlled trial (RCTcRCT) of participatory women's groups in rural Nepal to improve neonatal survival (2001-2003) (Manandhar et al. 2004). The follow-up study was designed to examine the long-term impact on disabilityfree survival in mothers and their offspring enrolled in the original trial. Participants were recruited from Makwanpur district only. The inclusion criteria were all children whose mothers had been pregnant during the original trial period (2001-2003) and who were alive and willing to participate in the follow-up study.

Full details of the original trial can be found elsewhere (Manandhar et al. 2004). In brief, the initial trial intervention consisted of community-based perinatal participatory women's groups facilitated by local women (non-health professionals). The groups investigated health issues around pregnancy, childbirth and newborn health through monthly meetings over 3 years. The primary outcome was neonatal mortality rate. Secondary outcomes included maternal mortality at 4 weeks. The study demonstrated a $30 \%$ reduction in neonatal mortality and a $78 \%$ reduction in maternal mortality in intervention clusters, compared with controls. (Manandhar et al. 2004). Pregnancies were followed until 4 weeks after delivery. (Manandhar et al. 2004; Osrin et al. 2003). The study was registered as an International Standard RCT (ISRCTN31137309).

\section{Prevalence Study Procedures}

In 2014-2015, two rounds of household interviews were conducted 6 months apart on all surviving and willing participants of the original trial (Haworth et al. 2017; Heys et al. 2016). Children from all clusters were included.

In the first wave of data collection, the questionnaire administered assessed survival, age and working memory for both mothers (10-word recall) and children (digit recall forward and backward). Mothers were also asked about reproductive history, literacy, smoking, diagnosis of hypertension and diabetes and psychological wellbeing. Additional child-specific topics included questions about childhood 


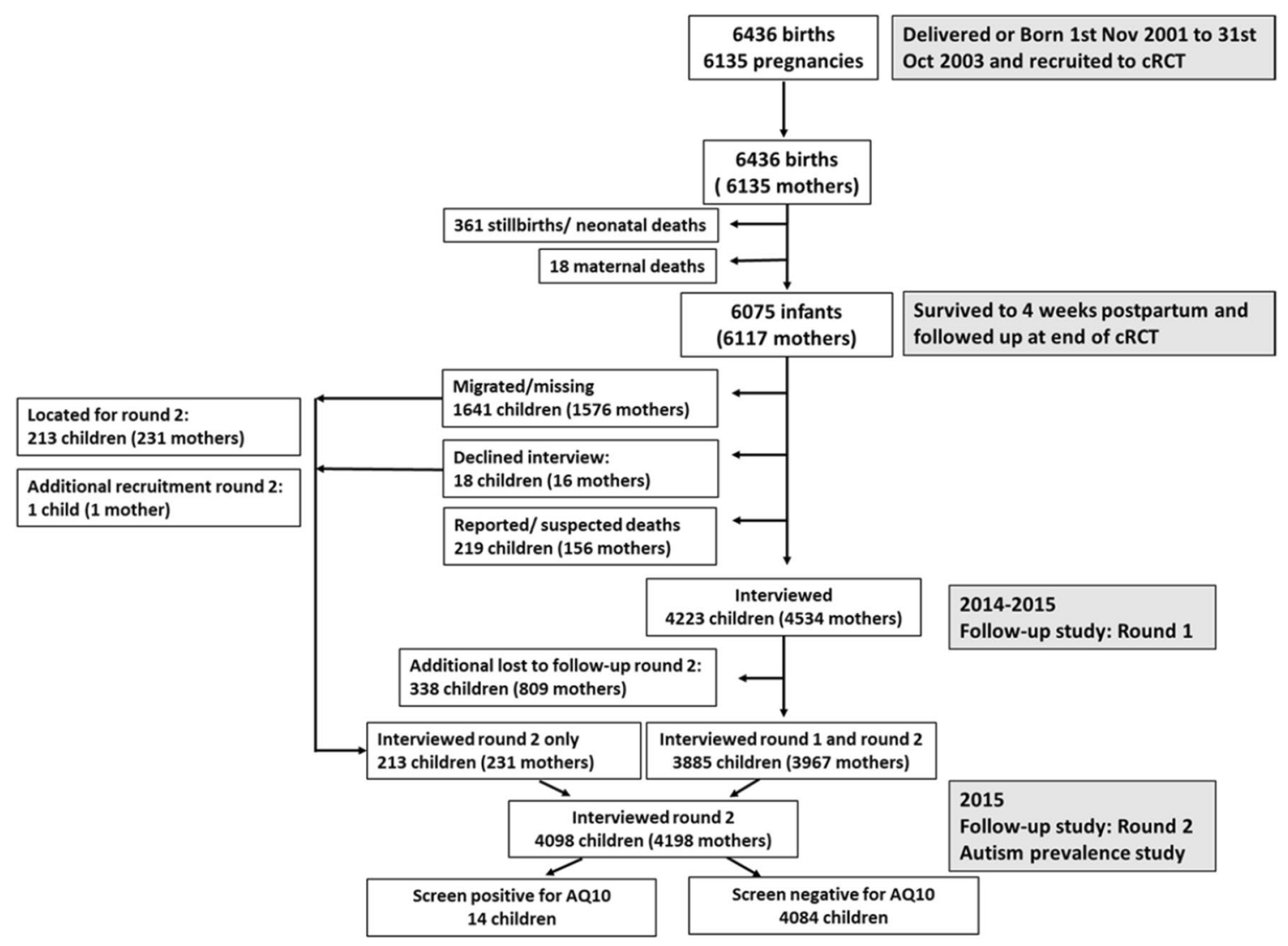

Fig. 1 Participant flow chart from baseline to follow-up in rounds 1 and 2

development and disability, school attendance and performance. Topics relating to the family overall included socioeconomic status (as measured by household asset, land, house and animal ownership) and household occupation. Blood pressure and anthropometric measures were taken from both mothers and children.

In the second wave of data collection 6 months later, child-specific topics included the Nepali AQ-10 (written version, described herein; see Appendix Table 5) and child pubertal status (Petersen et al. 1988); maternal-specific questions included an assessment of maternal empowerment (Cunningham et al. 2015) and perceived social support (Kvaal et al. 2014); and family-specific questions focused on an assessment of family socio-economic status using the Oxford Multi-poverty Index (Alkire 2010). Critically, data pertaining to this autism prevalence study were collected in round 2 of the follow-up study only.

\section{Prevalence Study Sample Size}

In total, we conducted face-to-face interviews with 4222 (wave 1) and 4098 (wave 2) maternal-infant dyads. Figure 1 shows the flow of participants from the original trial population through to the AQ-10 follow-up in wave 2.

\section{Prevalence Study Pilot Studies}

Pilot studies were carried out for both waves of data collection. Research tools for the first round were piloted with 531 mother-child pairs, chosen randomly from original records in six clusters (three control and three intervention). The six clusters were randomly selected stratified by original trial allocation status. The first 100 mother-child pairs were then selected by birth date from the six clusters for the pilot study, with an aim to assess approximately 500 mother-child pairs. Of the 531 mother-child pairs who participated in wave 1 data collection, 152 of these were selected at random to participate in wave 2, 6 months later. Analysis of pilot data and field interviewer feedback were used after both pilots to revise the final questionnaires and databases and to provide additional field worker training (e.g., around measurement of body size and blood pressure). Following the pilot studies, minor edits were made only to other parts of the questionnaire and none to the disability questions (round 1) and Nepali AQ-10 (round 2). Therefore, results from the pilot and main study are presented together for the purposes of these analyses. 


\section{Prevalence Study Outcome Measures}

Two screening tools were used for the primary and secondary outcomes, namely the adapted Nepali version of the AQ-10 and the Module on Child Functioning and Disability (MCFD), respectively. The primary outcome of interest was likelihood of autism measured by the Nepali AQ-10 and defined as a score of 6 or more out of 10 (cf. Allison et al. 2012).

The secondary outcome of interest, collected during wave 1 of data collection, was report of social and communication difficulties, as well as physical, learning and behavioral disability using the Module on Child Functioning and Disability (MCFD) produced by UNICEF and the Washington Group on disability statistics (UNICEF 2014) for use in children and young people aged 2-17 years. The MCFD is a new screening tool which builds on the established short set of questions for adult disability screening (Washington Group on Disability Statistics 2006; Washington Group on Disability Statistics and; UNICEF 2014), and is being developed as a gold standard epidemiological measure of disability prevalence. The screening tool is in the final phases of validation testing and we received permission to use it in the current study. It is carried out by interview with the child's main caregiver to assess functioning across seven core functional domains, with a total of 19 questions, namely: speech and language, hearing, vision, cognition, mobility, self-care and emotions and behavior (see Appendix Table 6). With the exception of three questions, participants rate each item on a scale ranging from no difficulty to cannot do at all. The three exceptions are questions around the use of hearing aids/glasses (yes/no response) and the question around propensity to feelings of sadness (three possible responses: the same or less, more or a lot more than age matched comparisons). Owing to the current absence of validity data on the questions around emotions and behaviors the UNICEF and the Washington Group on disability statistics have advised the definition of disability to be the report of at least some difficulty in at least one of speech and language, hearing, vision, learning, mobility and motor skills-the core functional domains, termed here as MCFD-core (Washington Group on Disability Statistics). Additional to questions on these seven domains, questions on behavior, attention, relationships, playing and coping with change were used as a comparative with the AQ-10 interview-termed here as MCFD-extended. A positive screen for these questions was defined as reporting at least some difficulty in each area (Washington Group on Disability Statistics). Sensitivity analysis was conducted using more stringent definition of a positive screen defined as a lot of difficulty or cannot do at all in at least one of these domains (as is typically used in the adult Washington disability screening tool).

\section{Supplementary Questions}

In wave 1 of screening, following the administration of the MCDF, parents were asked a series of questions around what support they received for their child, if they had screened positive for disability. In particular, they were asked if they had applied for, had received and/or had used a government disability card. These cards have four color coded categories: red (completely affected); blue (severely affected); yellow (moderately affected); white (persons with mild or ordinary disabilities). Persons who have these cards have additional financial benefits from the government and also priority over some government transport and health care. Participants were also asked about school attendance (historical and current) and whether they had received any support (in the form of counselling, medical equipment, transport or financial support) from non-government organizations (NGOs). Weight and height measured in wave 1 were used to estimate stunting of growth.

\section{Statistical Analysis}

Quantitative statistical analyses were performed using Stata version 14.0 (StataCorp., 2015). Fischer's exact test and Chisquared tests were used as appropriate for univariate analysis of categorical variables and t-tests for univariate analysis of continuous variables. A p-value of less than or equal to 0.05 was interpreted as being statistically significant.

Ethical approval for the follow-up study was obtained both from Nepal Health Research Council and the University Research Ethics Committee. All participants gave informed verbal consent prior to participation, which is more culturally appropriate in this setting than written consent and suited to the low educational achievement/level and literacy rates of the participants.

\section{Results}

\section{Preliminary Screening-Tool Acceptability Study}

Parents of children with and without a known diagnosis of autism considered the AQ-10 items to be acceptable and straightforward to answer (see Table 2) - but not without caution. We identified two themes in parents' responses reflecting the potential challenges related to probing for atypical behaviors and/or autism. They suggested that parents of children with no known diagnosis of autism (1) would not know enough about child development to be able to recognize atypical behaviors and (2) would find a potential diagnosis of autism challenging to accept or endorse. One parent of an autistic child summed up this latter point: "They will not take it [i.e., a diagnosis of 
Table 2 Sample quotes from focus groups exploring the perceived acceptability of the AQ-10 by the two parent groups (those with and those without a child with a known diagnosis of autism) depending on whether the parent answering the AQ-10 had a child with or without a known diagnosis of autism

Perceived acceptability if parents answering the AQ-10 Perceived acceptability If parents answering the AQ-10

had a child without a known diagnosis of autism had a child with a known diagnosis of autism

$\begin{aligned} & \text { Feedback from parent group } \\ & \text { Parents of children without } \\ & \text { a known diagnosis of } \\ & \text { autism }\end{aligned}$
"It is easy if we know how to speak"
"It is easy that we answer as we thought"
"This is all about domestic question which we have
already done in our daily lives so we feel it is easy"
"They can't" [answer the questions] "most of the
parents can't give answers who don't know about
autism"
"Firstly, they will not [be] willing to give answers and
known diagnosis of autism
secondly they will not accept to talk with you saying
it is useless"
"They can't say as we did"
"Normal children's parents also will not give answer.
They don't in how much communication and social
behaves develops in children according to their age
grow up. They don't know because of lack of aware-
ness"
"Most of the parents can't give answers who don't
know about autism. Firstly, they will not [be] willing
to give answer and secondly they will not accept to
talk with you saying it is useless. They can't say as
we did"

"They mind if their children suffer"

"Perhaps, it is easy"

"Perhaps, they feel difficult because their children are suffering from that type of problems"

"It is usually happening"

"[because] we already know about that and we are facing that too"

"We didn't feel it difficult, it is normal" autism] easy. Nowadays, all the parents expect that my son will be a big businessman, engineer and doctor. But they don't expect anything from the autistic children but it does not mean that autistic children have no capacity. On average, they think autistic children can't do anything and they feel them as a useless thing of society. If we try to make them aware, they will not hear us. They think spending money on autistic children is like putting water on sand."

\section{Prevalence Study}

Of the 4098 parents of surviving children interviewed in round 2 for this autism prevalence study, 14 scored 6 or greater out of 10 , indicative of autistic symptomatology. Mean AQ-10 scores for those who screened positive on the AQ-10 was 7.9 (SD 1.5), with median of 8 (interquartile range 7-9); for those screening negative, 0.1 (SD 0.5), median $0,95.4 \%$ of the cohort scored 0 out of 10 . In these 4098 children, the prevalence of disability using the most inclusive definition of disability as at least some difficulty in one or more of the core domains was $7.4 \%$. Prevalence of disability using more stringent cut offs provided the following prevalence: MCFD-core reporting a lot of difficulty in at least one domain: $1.0 \%$ and MCFD-core reporting cannot do at all in at least one domain: $0.3 \%$.
Figure 2 shows the proportion of children by AQ- 10 score from 0 to 10 and the proportion of children by AQ-10 score from 1 to 10 inclusive, thus more clearly visualising the distribution in scores of 1 and above. These scores are shown for four groups, namely: (1) all children, (2) children screening positive for the MCFD-core disability questions, (3) children screening positive for the MCFD-extended questions and (4) children screening positive for the 3 questions most intuitively associated with autistic symptomology-denoted in Fig. 2 as MCFD-autism. The AQ-10 scores for children who scored postitive for the extended MCFD questions and for the MCFD-autism questions were spread more evenly across the potential AQ-10 scores from 0 to 10 , with a greater number of children showing higher AQ-10 scores. Mean AQ-10 scores for the four groups of children were as follows: (1) all children: $\mathrm{M}=0.12(\mathrm{SD}=0.66)$; (2) MCFD-core disability: $\mathrm{M}=0.55(\mathrm{SD}=1.82)$ and (3) MCFDextended: $\mathrm{M}=1.36(\mathrm{SD}=2.88)$ and (4) $\mathrm{MCFD}$-autism: $\mathrm{M}=1.94(\mathrm{SD}=3.31)$.

Table 3 describes key characteristics of the 14 children who scored 6 or more out of 10 in the AQ-10. Almost twothirds $(65 \%)$ were male, which compares to $51 \%$ males in the cohort as a whole, and their mean age, 11.4 years (range 10.5-12.3), was similar to the entire cohort. Thirteen out of 14 screened positive for disability on the MCFD and 12 


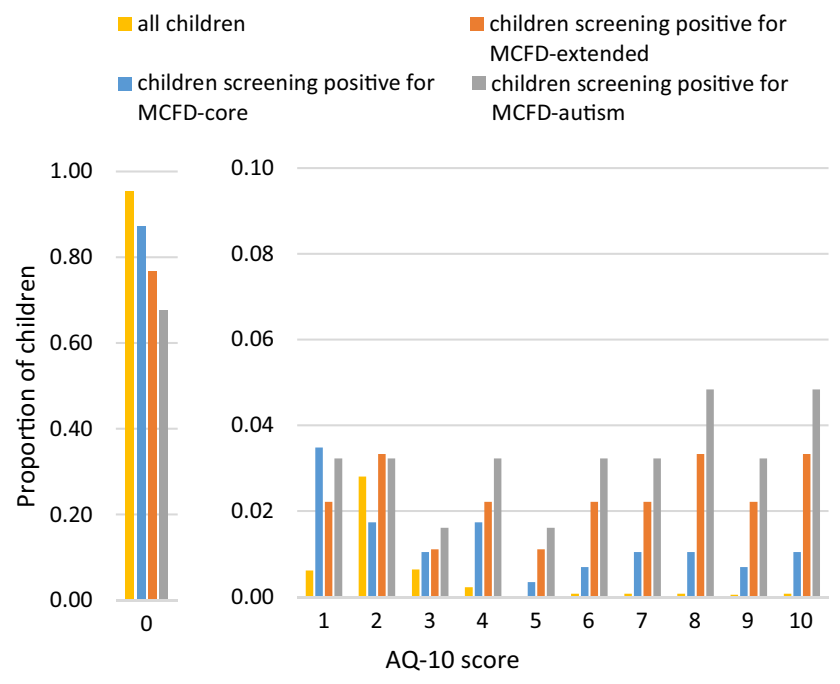

Fig. 2 Proportion of children by AQ10 score. Proportions are shown for four groups of children, namely: (1) all children, (2) children who screen positive for MCFD-core; (3) children who screen positive for MCFD-extended and (4) children who screen positive for MCFDextended questions most intuitively associated with autism symptomatology-MCFD-autism. AQ-10 Autism quotient-10, MCFD module of child functioning and disability

screened positive for difficulties in communication, forming relationships with others, coping with change, playing with other children and attention (see Table 4). None of the children had a known diagnosis of autism. One child screened positive for AQ-10 (score 6 out of 10) but negative for all of the disability screen (Table 3: Child 1). Out of the 14 children screening positive, this child was one of only 4 children who attended school and the only child of the 14 who was able to complete the digit recall forward and backward scoring below average on both scores (digit recall forward 4: M for cohort $=4.8, \mathrm{SD}=1.1$; digit recall backward 3: $\mathrm{M}=3.1$, $\mathrm{SD}=1.6)$. The majority of the 14 children screening positive (71\%) did not attend school, compared with $4 \%$ of the cohort, and $83 \%$ had stunted growth compared with $39.6 \%$ of the cohort. A child is said to have stunted growth when their height for age is $<2$ standard deviations of the WHO child growth standards median. Five families had applied for the government disability card (see Table 3) and, of the four who had received one, two had used it. The same two families had received financial support from an NGO. Of note, children who screened positive for the AQ-10 were equally as likely to be in the intervention or control arm of the original trial with 7 children in each trial arm (p-value for chi-squared, 0.945).

Using questions from the MCFD extended screen, we created a composite score by summing the three questions most intuitively associated with autism symptomatology, namely coping with changes, social relationships and playing with others-denoted in Fig. 2 as MCFD-autism. Figure 2 shows a histogram of this composite score from the subset disability screening, excluding those children with a score of zero. Of the 4222 children, this composite score identified $66(1.6 \% ; 39$ males; $\mathrm{M}$ age $=11.4$ years, $\mathrm{SD}=0.6)$ who screened positive for reporting a problem in one or more of these areas. Of these 66 children, $62(94 \%)$ received the AQ-10 in round 2, 6 months later, with mean AQ-10 scores of $1.94(\mathrm{SD}=3.31$, range $0-10)$ - which were significantly higher $(\mathrm{p}<0.001)$ than the scores from the remaining cohort $(\mathrm{n}=3,822 ; \mathrm{M}=0.1, \mathrm{SD}=0.47)$. Of these 62 children, 20 (32\%) scored 1 or more out of 10 on the AQ- 10 .

\section{Discussion}

This is one of only two published studies to date to have estimated the prevalence of autism in a rural LIC setting. The study showed that the adapted AQ-10 was acceptable to groups of parents of children both with and without a known diagnosis of autism. Of the 4098 children sampled, 14 scored positive for autistic symptomatology. The demographic, anthropometric, clinical and educational characteristics and gender ratio of these 14 children indicate that the AQ-10 administered with a threshold score of 6 or above in this population is likely to identify children with complex needs and more likely more severe autism. 66 out of 422 children screened positive for the three questions most intuitively associated with autism symptomatology from the MCFD disability screening tool. A comparison of scores from the AQ-10 to those from the MCFD administered 6 months earlier provided some evidence of the clinical validity of the AQ-10. Likewise, the comparison of scores from these two tools provided evidence of the potential of MCFD, at least the section pertaining to child behavior, to identify successfully children within the population with atypical child development and behaviors.

There is no population-based study with which to compare these AQ-10 scores. The original paper describing the AQ-10 as a short screening tool was tested on UK cases (autistic children and adults) and controls (children and adults without a known diagnosis of autism) (Allison et al. 2012). The autistic adolescents scored a mean of 8.40 (SD 1.69) and adolescent controls a mean of 1.78 (SD 1.80). The AQ-10 scores for UK cases were therefore not dissimilar to those from this cohort who screened positive with AQ-10 scores ( $\mathrm{M}=7.9$; SD 1.5). However, the Nepali population mean scores were much lower than those of the control group tested in the UK study.

If the AQ-10 screening tool is as sensitive and specific in the Nepali population as it is in the UK, the current results would give an estimated true prevalence of 3 in 1000 (95\% confidence interval: $2-5$ in 1000) (Brown et al. 2001). The 
Table 3 Characteristics of children with scores of 6 or more out of 10 on the AQ-10

\begin{tabular}{|c|c|c|c|c|c|c|c|c|c|}
\hline Child & Gender & Age (years) & $\begin{array}{l}\text { Maternal age } \\
\text { at follow-up } \\
\text { (years) }\end{array}$ & $\begin{array}{l}\text { Family } \\
\text { ethnicity }^{\text {a }}\end{array}$ & AQ-10 score & $\begin{array}{l}\text { Positive or } \\
\text { negative } \\
\text { screen for } \\
\text { disability }\end{array}$ & $\begin{array}{l}\text { MCFD dis- } \\
\text { ability score } \\
\text { (out of } 12 \text { ) }\end{array}$ & $\begin{array}{l}\text { Ever } \\
\text { attended } \\
\text { school }\end{array}$ & $\begin{array}{l}\text { Attends school } \\
\text { now }\end{array}$ \\
\hline 1 & Girl & 12.4 & 38.1 & Tamang & 6 & Negative & - & Yes & Yes \\
\hline 2 & Boy & 12.3 & 37.3 & Brahmin & 8 & Positive & 7 & No & No \\
\hline 3 & Boy & 11.7 & 38.8 & Tamang & 7 & Positive & 11 & No & No \\
\hline 4 & Girl & 10.7 & 29.7 & Pariyar & 8 & Positive & 11 & Yes & Yes \\
\hline 5 & Boy & 10.8 & 48.3 & Tamang & 10 & Positive & 9 & No & No \\
\hline 6 & Boy & 11.0 & 40.5 & Tamang & 10 & Positive & 8 & No & No \\
\hline 7 & Boy & 11.6 & 35.4 & Brahmin & 9 & Positive & 8 & No & No \\
\hline 8 & Boy & 12.1 & 55.8 & Tamang & 8 & Positive & 12 & Yes & Yes \\
\hline 9 & Girl & 10.5 & 36.2 & Chhetri & 9 & Positive & 10 & No & No \\
\hline 10 & Girl & 11.0 & 42.3 & Tamang & 6 & Positive & 9 & No & No \\
\hline 11 & Girl & 12.3 & 32.4 & Tamang & 7 & Positive & 11 & No & No \\
\hline 12 & Boy & 11.5 & 39.0 & Tamang & 6 & Positive & 9 & No & No \\
\hline 13 & Girl & 11.7 & 39.3 & Pariyar & 10 & Positive & 10 & No & No \\
\hline 14 & Boy & 11.9 & 40 & Tamang & 7 & Positive & 2 & Yes & Yes \\
\hline Child & $\begin{array}{l}\text { Stunted } \\
\text { growth }\end{array}$ & $\begin{array}{l}7 \text { Digit recall } \\
\text { (forward) } \\
\text { (mean 4.8, } \\
\text { SD 1.1) }\end{array}$ & $\begin{array}{l}7 \text { Digit recall } \\
\text { (back; mean } \\
3.1, S D 1.6 \text { ) }\end{array}$ & $\begin{array}{l}\text { Applied for } \\
\text { disability } \\
\text { card }\end{array}$ & $\begin{array}{l}\text { Has disabil- } \\
\text { ity card }\end{array}$ & $\begin{array}{l}\text { Colour of } \\
\text { disability } \\
\text { card }^{b}\end{array}$ & $\begin{array}{l}\text { Used disabil- } \\
\text { ity card? }\end{array}$ & $\begin{array}{l}\text { Received } \\
\text { support from } \\
\text { NGO }\end{array}$ & $\begin{array}{l}\text { What type of } \\
\text { support from } \\
\text { NGO }\end{array}$ \\
\hline 1 & No & 4 & 3 & - & - & - & - & - & - \\
\hline 2 & No & 0 & 0 & Yes & Yes & Blue & No & No & - \\
\hline 3 & Stunted & 0 & 0 & Yes & Yes & Blue & Yes & Yes & Financial \\
\hline 4 & Stunted & 3 & 0 & No & - & - & - & No & - \\
\hline 5 & Stunted & 0 & 0 & No & - & - & - & No & - \\
\hline 6 & Stunted & 0 & 0 & No & - & - & - & No & - \\
\hline 7 & - & 0 & 0 & No & - & - & - & No & - \\
\hline 8 & Stunted & 0 & 0 & Yes & Yes & Blue & No & No & - \\
\hline 9 & Stunted & 0 & 0 & No & - & - & - & No & - \\
\hline 10 & Stunted & 0 & 0 & No & - & - & - & No & - \\
\hline 11 & Stunted & 0 & 0 & Yes & Yes & Red & No & No & - \\
\hline 12 & Stunted & 0 & 0 & Yes & No & - & - & No & - \\
\hline 13 & - & 0 & 0 & Yes & Yes & Red & Yes & Yes & Financial \\
\hline 14 & Stunted & 3 & 0 & No & - & - & - & No & - \\
\hline
\end{tabular}

MCFD Module on childhood functioning and disability, $N G O$ non-government organisation

${ }^{a}$ Ethnicity: Brahman and Chhetri are high Caste people and are highly privileged. Tamang are hill ethnic people and do not belong to the caste system, Pariyar are are low caste people, so called "untouchables" and economically poor

${ }^{b}$ Government disability card: red: completely affected; blue: severely affected; yellow: moderately affected; white: persons with mild or ordinary disabilities

current population of children under 18 years in Nepal is a little over 11.6 million. If confirmed, these prevalence estimates would equate to 34,803 children and young people currently living in Nepal (range 23,203-58,007) with a potential diagnosis of autism. The number of children with a current diagnosis of autism $(n=107)$; Kathmandu Valley, 2012 estimates (Autism Care Society Nepal) is substantially lower than this figure. This estimated prevalence of 3 per 1000 is lower than that in HICs, which is reported as 10-20 per 1000 (Elsabbagh et al. 2012), and lower than the only other LIC study showing Ugandan population estimates in 1-10-year-olds to be $12-13$ per 1000 (Kakooza-Mwesige et al. 2014). Nevertheless, this estimate is higher than global median estimates (1.7/1000) and estimates from a recent study in rural India 0.9 per 1000 for all children in the full cohort of 11,000 children aged between 1 and 10 years and 1.1 per 1000 in the rural cohort (Raina et al. 2017). In the latter study, urban rural abode and higher socio-economic class 
Table 4 Numbers of children screening positive for both the AQ-10 and overall disability and specific questions around social and communication

\begin{tabular}{|c|c|c|c|c|}
\hline \multirow[t]{2}{*}{ Disability measures by MCFD } & & \multicolumn{2}{|l|}{ AQ-10 } & \multirow{2}{*}{$\begin{array}{l}\text { p-value } \\
\text { (Fischer's } \\
\text { exact) }\end{array}$} \\
\hline & & Positive & Negative & \\
\hline \multicolumn{5}{|l|}{ Overall disability } \\
\hline \multirow[t]{2}{*}{ Disability (MCFD-core) $^{\mathrm{a}}$} & Positive & 13 & 274 & $<0.001$ \\
\hline & Negative & 1 & 3596 & \\
\hline \multirow[t]{2}{*}{ All disability (MCFD-core plus extended) ${ }^{\mathrm{b}}$} & Positive & 13 & 213 & $<0.001$ \\
\hline & Negative & 1 & 3558 & \\
\hline \multicolumn{5}{|l|}{ Subtype disability } \\
\hline \multirow[t]{2}{*}{ Physical disability } & Positive & 12 & 222 & $<0.001$ \\
\hline & Negative & 2 & 3648 & \\
\hline \multirow[t]{2}{*}{ Learning disability } & Positive & 13 & 89 & $<0.001$ \\
\hline & Negative & 1 & 3782 & \\
\hline \multirow[t]{2}{*}{ Behavioural disability } & Positive & 11 & 53 & $<0.001$ \\
\hline & Negative & 3 & 3832 & \\
\hline \multirow[t]{2}{*}{ Difficulties in coping with change } & Positive & 12 & 34 & $<0.001$ \\
\hline & Negative & 2 & 3837 & \\
\hline \multirow[t]{2}{*}{ Difficulties in social relationships } & Positive & 12 & 17 & $<0.001$ \\
\hline & Negative & 2 & 3854 & \\
\hline \multirow[t]{2}{*}{ Difficulties in playing with others } & Positive & 12 & 25 & $<0.001$ \\
\hline & Negative & 2 & 3846 & \\
\hline \multirow[t]{2}{*}{ Attention difficulties } & Positive & 12 & 32 & $<0.001$ \\
\hline & Negative & 2 & 3839 & \\
\hline
\end{tabular}

$M C F D$ Module on childhood functioning and disability

${ }^{a}$ Measured by positive report of difficulty in domains of seeing, hearing, speech and language, mobility, self-care and cognition

${ }^{\mathrm{b}}$ Including on six core domains and the additional report of emotional and/or behavioural difficulties were associated with reduced prevalence. The closest areas geographically, other than India, in which there is some (but still not a significant amount of) research on autism prevalence available are Sri Lanka and Indonesia. One, relatively old Indonesian-based study estimated 1.7 cases of autism per 1000 of the population (Wignyosumarto et al. 1992). In comparison, a study based in Sri Lanka placed the estimate as high as 10 per 1000 (Perera et al. 2009).

Of those children who screened positive for autism symptomatology, almost all also screened positive for physical, learning and behavioral disabilities. Given these two screening tools were delivered approximately 6 months apart, this finding provides preliminary evidence that our modified AQ-10 is a valid measure of atypical child behavior. It also suggests that those children who screened positive for autism symptomatology on the AQ-10 have evidence of multiple impairments and so most likely represent the severe end of the spectrum of potential clinical presentations of autism. This is also reflected in the gender ratio (1.4:1, $\mathrm{M}: \mathrm{F}$ ), showing a much higher number of females than is typically reported in the full spectrum of autism, around 4:1 (Fombonne 2009); though see (Loomes et al. 2017). In autistic children who are cognitively less able, the gender ratio falls from 10:1 to be closer to 1:1 (Volkmar et al. 1993). It is therefore likely that our estimated prevalence of 3 per 1000 is an underestimation of the true prevalence of autism within this population. This is also reflected in the number of children (66 of 4222) screening positive for difficulty in at least one of the areas of coping with changes, social relationships and playing with others. These questions have not yet been validated or indeed tested in any way as a screen for autism. Yet if it were assumed that a positive screen was indicative of likelihood of autism, this figure would equate to an estimated prevalence of 16 per 1000, much more similar to HIC estimates and those from Uganda. Indeed, the Ugandan study used an adaptation of the Ten questions questionnaire that was the basis for the MCFD used in this study (Kakooza-Mwesige et al. 2014).

In addition to being more likely to screen positive for physical, learning and behavioral disabilities, children who screened positive for autism symptomatology were more likely to be stunted and to have cognitive difficulties (as measured by marked difficulties completing the forward and backward digit recall, a measure of working memory). The majority of these children were not attending education and were unlikely to be receiving any financial support 
despite having significant difficulties. An $83 \%$ stunting rate is substantial. Nutritional deficits in children with disabilities and learning difficulties are common and can not only be a cause of cognitive deficits, but also contribute to the failure to reach full developmental potential in the presence of a developmental condition. These limited, but important descriptive data support the general opinion that children with all kinds of atypical child development and disability are a highly vulnerable, disadvantaged group, especially in resource-limited settings such as Nepal (UNICEF 2013).

The strengths of our study include (1) its novelty-to our knowledge there is only one other published study of prevalence estimates in a LIC; (2) the interview of families within households, thus including children who were not present in school; (3) our restricted age range, thus rendering age range less of a confounding variable; and (4) our cultural adaptation of the screening tool using qualitative methods in collaboration with local stakeholders (Stewart and Lee 2017). Also, to our knowledge, no other study has incorporated cultural constructions of mind/emotions and local notions of childhood/children in the translation and piloting of the AQ-10 or similar tools. We also situated our prevalence estimate within the context of other important data, including disability screen, school attendance and growth with which to explore characteristics of those screening positive for AQ-10.

There are, however, limitations to our study. First, the cohort is derived from mother-infant dyads who were enrolled in a perinatal trial. Nevertheless, children who screened positive for the AQ-10 were equally as likely to have been born into the villages enrolled in the intervention as those villages enrolled in the control. Second, the MCFD is under development and indeed since the commencement of this study minor edits have been made to the questions. In addition, early testing in India and Cameroon, coupled with the prevalence found here, suggest cultural interpretation of degree of difficulty may greatly influence reporting (Mactaggart et al. 2016). For instance, prevalence of reporting at least some difficulty in at least one domain was 35\% and 64\% in India and Cameroon, respectively, whereas prevalence of reporting a lot of difficulty or cannot do in at least one domain was 4 and 9\% again in India and Cameroon, respectively (Mactaggart et al. 2016). Thus, our comparison of MCFDextended questions with AQ-10 here should be considered exploratory. Notably, however, our prevalence estimate of $7.4 \%$ is in keeping with a systematic review of the global estimates of childhood disability in LMICs which suggested that despite a wide range in estimates $(0.5-18 \%)$, the majority clustered around 5-10\% (Maulik and Darmstadt 2007).

Future research is required to validate the AQ-10 and the MCFD-core and -extended modules through in-depth comprehensive assessments of high-scoring children and a representative sample of low-scoring children. Given the wide range of perinatal data available for this cohort, we also have the unique opportunity to conduct an exploratory study around the association of perinatal factors with likelihood of autism symptomatology in a population of children with poor nutrition ( $40 \%$ stunting at mean age of 11.5 years). Such prevalence research, however, also raises serious ethical concerns, including the possibility of disclosure of likelihood of and/or even a diagnosis of autism in a population for whom there is no term for autism (see Heys et al. 2016) and there is very little health or education provision to support children and families with a diagnosis of autism. These issues surrounding the ethics and logistics of diagnostic disclosure were precisely the ones that our focus group participants perceived to be of concern. There are also no validated diagnostic tools available for use in the Nepali population, rendering a validation study even more challenging. Thorough examination of these issues with Nepali parents and practitioners is essential prior to pursuing further the validation study of the AQ-10, including examining the potential impact of disclosure of a diagnosis of, or likelihood of a diagnosis of autism about which very little is known in most resource-poor settings like Nepal. Finally, future research in this area should explore the potential impact of caste/ethnicity and rural/urban divide on understanding of autism and its implications.

In our qualitative study of Nepali parents' and professionals' understanding of typical and atypical child development (with an emphasis on autistic symptomatology), we found that parents of children without a diagnosis of autism and professionals in general had little explicit awareness of autism (Heys et al. 2016). Only parents of autistic children, pediatricians and the disability sector worker identified behaviors typically associated with autism as 'autistic'. Other participants, including parents of children without an autism diagnosis, primary and early child development teachers, community health workers and faith healers, used distinctive terms, such as "stubborn" and "insisting" to distinguish vignettes of autistic children from vignettes of children with other developmental conditions. Most participants felt that environmental factors, including in-utero stressors and birth complications, parenting style, and home or school environment, were key causes of atypical child development and further called for greater efforts to raise awareness and build community capacity to address autism. Thus, the preliminary prevalence estimate reported herein, combined with complementary research showing the lack of awareness of autism by Nepali professionals and parents, demonstrates a substantial unmet need and stresses the importance of developing services to support families and children with atypical development in LIC settings.

Acknowledgments We are grateful to all of the participants who so generously gave up their time to take part in the study, to Autism Care Society Nepal for hosting training days for the researchers and to the Mother and Infant Research Activities, Nepal, senior research team: Mangalmaya Manandhar, Rita Shrestha, Dhurba Adhikari, Jyoti 
Bamjan, Bharat Budhathoki, Dej Krishna Shrestha and Sagar Khadka. We also thank Dr. Melissa Neuman for her data cleaning of the original trial dataset and Claudia Cappa, Statistics and Monitoring Specialist Statistics and Monitoring Section, Division of Policy and Strategy, UNICEF, USA and Mitchell Loeb from the Office of Analysis and Epidemiology, National Center for Health Statistics, USA, and the UN/ Washington Module on Child Health Functioning group for sharing the Module on Child Functioning and Disability (MCFD) with us and Prof. J. Katz for sharing their group's Nepali translation of the Ten questions questionnaire and Amy Alexander for her help with analysis of the qualitative data. The facilitator training and focus group work for this project was funded by a grant awarded to M.H., E.P., and A.C. from the Institute of Education (IOE)/UCL Strategic Partnership Incubator Fund. M.H. was funded by the National Institute for Health Research, UK, during this project. E.P. was funded by a Philip Leverhulme Prize from the Leverhulme Trust, UK. Research at the Centre for Research in Autism and Education (CRAE) is supported by The Clothworkers' Foundation and Pears Foundation. The study was funded by a Wellcome Trust strategic award. Ref: 085417/Z/08/Z, Project Title: "Population Science of Maternal and Child Survival."

Author Contributions MH, DM, EP and AC conceived of the study and drafted the manuscript. MH, DM, EP, AC, MW, KMT, MS, EM and FG participated in its design and coordination. EH, FG and EM participated in the design and interpretation of the data and helped to draft the manuscript. $\mathrm{MH}$ performed the statistical analysis. $\mathrm{MH}$, EM and EP performed the qualitative analysis. All authors read and approved the final manuscript.

Funding The facilitator training and focus group work for this project was funded by a University Strategic Partnership Incubator Fund awarded to MH, AC and EP. The first author was funded by a National Institute of Health (NIHR) clinical academic lectureship. The final author (EP) was funded by a Philip Leverhulme Prize from the Leverhulme Trust, UK. The field work for the study was funded by a
Wellcome Trust strategic award. Ref: 085417/Z/08/Z, Project Title: "Population Science of Maternal and Child Survival."

\section{Compliance with Ethical Standards}

Conflict of interest All authors declare that they have no conflict of interest.

Ethical Approval Ethical approval was obtained from the University College London ethics committee (Project ID: 5143/002) and the Nepal Health Research Council (Reg.no.L99/2OL3). All procedures performed in studies involving human participants were in accordance with the ethical standards of the university and the Nepali national research committee and with the 1964 Helsinki declaration and its later amendments or comparable ethical standards.

Informed Consent All participants gave informed verbal consent prior to participation, which is more culturally appropriate in this setting than written consent and suited to the low educational achievement/level and literacy rates of the participants.

Open Access This article is distributed under the terms of the Creative Commons Attribution 4.0 International License (http://creativeco mmons.org/licenses/by/4.0/), which permits unrestricted use, distribution, and reproduction in any medium, provided you give appropriate credit to the original author(s) and the source, provide a link to the Creative Commons license, and indicate if changes were made.

\section{Appendix}

See Tables 5 and 6.

Table 5 AQ-10 questionnaire (English/Nepali)

1.यो बचचाले जुनसुके क्याकलाप गर्दा सधै एकै तरकाले गर्ने वा बुझ्ने गर्छ? S/he notices patterns in things all the time.

$1=$ गरछे Yes $0=$ गरदेन No

2. कुनै पर्ना बस्तुगत अवलोकन गर्दा समग्र रुपमा नभएर सुक्ष्म रुपमा अवलोकन गर्छ? S/he usually concentrates more on the small details rather than the whole picture.

$1=$ गरछ Yes $0=$ गरदेन No

3. यो बंच्चाले सामाज्जक समुहमा बभिन्न प्रकारका व्यक्तहिरुको बार्तालापलाई सजलि पहल्याउन सक्छ? In a social groups/he can easily keep track of several different people's conversations.

$1=$ सक्छ Yes $0=$ सक्दैन No

4. एउटा कृयाकालापबांट अरको कृयाकालापमा सहजै सहभागी हुन् सक्छ र फर्के पुरानै कृयाकलाप जारी राख्न सक्छ? If there is an interruption, s/he can switch back to what s/he was doing very quickly.

$1=$ सकछ Yes $0=$ सक्देन No

5. यो बंच्चाले आफ्ना सहकर्मीहरुसंग कसरी कुराकानी गररिहने भनेर जान्देन? S/he does not know how to keep a conversation going with his/her peers

$1=$ जानदछ Yes $0=$ जानदेन No

6. यो बच्चा सामाजकि गफंगाफ (कुराकानी) गर्नमा राम्रो छ ? S/he is good at social chit-chat

$1=$ छ Yes $0=$ छेन No

7. यो बच्चा सानो छंदा ऊ साथीहरुसंग काल्पनकि खेल खेल्न मन पराउँथयो ?

When s/he was young s/he used to enjoy playing games involving pretending with other children?

$1=$ पराउँथयो Yes $0=$ पराउँदेनथयो No

8. कथा पढ्दा वा सुन्दा कथाको पात्रको भावना तथा मनसाय अड्कल लगाउन गाह्रो हुन्छ ?, s/he finds it difficult to imagine what it would be like to be someone else

$1=$ हुनछ Yes $0=$ हुँदैन No

9. यो बंच्चाले सामाजाकि अवस्था सजलिो महसुस गर्छ/ S/he finds social situation easy

$1=$ गरछ Yes $0=$ गरदेन No

10. यो बच्चालाई नयाँ साथा बनाउन गाह्रो हुन्छ/ S/he finds it hard to make new friends

$1=$ हुन्छ Yes $0=$ हुँदैन No 
Table 6 Module on child functioning and disability

\begin{tabular}{llll}
\hline Seeing & Children aged 2-17 & Does [name] wear glasses or contact lenses? & $1=$ Yes \\
$0=$ No
\end{tabular}

\begin{tabular}{|c|c|c|c|}
\hline & & $\begin{array}{l}\text { [if wears glasses] } \\
\text { Does [name] have difficulty seeing, when wearing his/her glasses? } \\
\text { Would you say... }\end{array}$ & $\begin{array}{l}1=\text { No difficulty } \\
2=\text { Some difficulty } \\
3=\text { A lot of difficulty } \\
4=\text { Cannot do at all }\end{array}$ \\
\hline & & [If child does NOT wear glasses] Does [name] have difficulty seeing? & $\begin{array}{l}1=\text { No difficulty } \\
2=\text { Some difficulty } \\
3=\text { A lot of difficulty } \\
4=\text { Cannot do at all }\end{array}$ \\
\hline \multirow[t]{3}{*}{ Hearing } & Children aged $2-17$ & Does [name] use a hearing aid? & $\begin{array}{l}1=\text { Yes } \\
0=\text { No }\end{array}$ \\
\hline & & $\begin{array}{l}\text { [If child uses a hearing aid] Does [name] have difficulty hearing, when } \\
\text { using his/her hearing aid(s)? }\end{array}$ & $\begin{array}{l}1=\text { No difficulty } \\
2=\text { Some difficulty } \\
3=\text { A lot of difficulty } \\
4=\text { Cannot do at all }\end{array}$ \\
\hline & & $\begin{array}{l}\text { [If child does NOT use a hearing aid] } \\
\text { Does [name] have difficulty hearing? }\end{array}$ & $\begin{array}{l}1=\text { No difficulty } \\
2=\text { Some difficulty } \\
3=\text { A lot of difficulty } \\
4=\text { Cannot do at all }\end{array}$ \\
\hline \multirow[t]{2}{*}{ Walking } & Children aged 5-17 & $\begin{array}{l}\text { Compared with children of the same age, does [name] have difficulty } \\
\text { walking } 500 \text { yards/meters on level ground? That would be about the } \\
\text { length of } 5 \text { football fields }\end{array}$ & $\begin{array}{l}1=\text { No difficulty } \\
2=\text { Some difficulty } \\
3=\text { A lot of difficulty } \\
4=\text { Cannot do at all }\end{array}$ \\
\hline & & $\begin{array}{l}\text { Compared with children of the same age, does [name] have difficulty } \\
\text { walking } 100 \text { yards/meters on level ground? That would be about the } \\
\text { length of } 1 \text { football field }\end{array}$ & $\begin{array}{l}1=\text { No difficulty } \\
2=\text { Some difficulty } \\
3=\text { A lot of difficulty } \\
4=\text { Cannot do at all }\end{array}$ \\
\hline Self-care & Children aged 5-17 & $\begin{array}{l}\text { Compared with children of the same age, does [name] have difficulty } \\
\text { with self-care such as feeding or dressing him/herself? }\end{array}$ & $\begin{array}{l}1=\text { No difficulty } \\
2=\text { Some difficulty } \\
3=\text { A lot of difficulty } \\
4=\text { Cannot do at all }\end{array}$ \\
\hline \multirow[t]{2}{*}{$\begin{array}{l}\text { Communication } \\
\text { and comprehen- } \\
\text { sion }\end{array}$} & Children aged 5-17 & $\begin{array}{l}\text { Compared with children of the same age and using [his/her] usual lan- } \\
\text { guage, does [name] have difficulty understanding other people? }\end{array}$ & $\begin{array}{l}1=\text { No difficulty } \\
2=\text { Some difficulty } \\
3=\text { A lot of difficulty } \\
4=\text { Cannot do at all }\end{array}$ \\
\hline & & $\begin{array}{l}\text { Compared with children of the same age and using [his/her] usual lan- } \\
\text { guage, does[name] have difficulty being understood by other people? }\end{array}$ & $\begin{array}{l}1=\text { No difficulty } \\
2=\text { Some difficulty } \\
3=\text { A lot of difficulty } \\
4=\text { Cannot do at all }\end{array}$ \\
\hline \multirow[t]{2}{*}{ Learning } & Children aged $3-17$ years & $\begin{array}{l}\text { Compared with children of the same age, does [name] have difficulty } \\
\text { learning to do new things? }\end{array}$ & $\begin{array}{l}1=\text { No difficulty } \\
2=\text { Some difficulty } \\
3=\text { A lot of difficulty } \\
4=\text { Cannot do at all }\end{array}$ \\
\hline & Children aged 5-17 & $\begin{array}{l}\text { Compared with children of the same age, does [name] have difficulty } \\
\text { remembering things that they have learned? }\end{array}$ & $\begin{array}{l}1=\text { No difficulty } \\
2=\text { Some difficulty } \\
3=\text { A lot of difficulty } \\
4=\text { Cannot do at all }\end{array}$ \\
\hline Emotions & Children aged 5-17 & $\begin{array}{l}\text { Compared with children of the same age, how much does [he /she] } \\
\text { worry or feel } \\
\text { sad? Would you say... [Read response categories] }\end{array}$ & $\begin{array}{l}1=\text { The same or less } \\
2=\text { More } \\
3=\text { A lot more }\end{array}$ \\
\hline Behaviour & Children aged 5-17 & $\begin{array}{l}\text { Compared with children of the same age, how much difficulty does } \\
\text { [name] have } \\
\text { controlling[his/her] behaviour? }\end{array}$ & $\begin{array}{l}1=\text { No difficulty } \\
2=\text { Some difficulty } \\
3=\text { A lot of difficulty } \\
4=\text { Cannot do at all }\end{array}$ \\
\hline Attention & Children aged 5-17 & $\begin{array}{l}\text { Compared with children of the same age, does [name] have difficulty } \\
\text { completing } \\
\text { a task? }\end{array}$ & $\begin{array}{l}1=\text { No difficulty } \\
2=\text { Some difficulty } \\
3=\text { A lot of difficulty } \\
4=\text { Cannot do at all }\end{array}$ \\
\hline
\end{tabular}


Table 6 (continued)

\begin{tabular}{|c|c|c|c|}
\hline Seeing & Children aged 2-17 & Does [name] wear glasses or contact lenses? & $\begin{array}{l}1=\text { Yes } \\
0=\text { No }\end{array}$ \\
\hline Coping with change & Children aged 5-17 & $\begin{array}{l}\text { Compared with children of the same age, does [name] have difficulty } \\
\text { accepting change to plans or routine? }\end{array}$ & $\begin{array}{l}1=\text { No difficulty } \\
2=\text { Some difficulty } \\
3=\text { A lot of difficulty } \\
4=\text { Cannot do at all }\end{array}$ \\
\hline Relationships & Children aged 5-17 & Does [name] have difficulty getting along with children of [his/her] age? & $\begin{array}{l}1=\text { No difficulty } \\
2=\text { Some difficulty } \\
3=\text { A lot of difficulty } \\
4=\text { Cannot do at all }\end{array}$ \\
\hline Playing & Children aged $2-12$ years & $\begin{array}{l}\text { Compared with children of the same age, does [name] have difficulty } \\
\text { playing } \\
\text { with other children? }\end{array}$ & $\begin{array}{l}1=\text { No difficulty } \\
2=\text { Some difficulty } \\
3=\text { A lot of difficulty } \\
4=\text { Cannot do at all }\end{array}$ \\
\hline
\end{tabular}

\section{References}

Abubakar, A., Ssewanyana, D., \& Newton, C. R. (2016). a systematic review of research on autism spectrum disorders in Sub-Saharan Africa. Behavioural Neurology 2016, 3501910. https://doi. org/10.1155/2016/3501910.

Alkire, S., \& Santos, M. E. (2010). Acute mutlidimensional poverty: A new index for developing countries. Working paper. Oxford Poverty and Human Development Initative (OPHI).

Allison, C., Auyeung, B., \& Baron-Cohen, S. (2012). Toward brief "Red Flags" for autism screening: The short autism spectrum quotient and the short quantitative checklist for autism in toddlers in 1,000 cases and 3,000 controls [corrected]. Journal of the American Academy of Child and Adolescent Psychiatry, 51, 202-212 e7. https://doi.org/10.1016/j.jaac.2011.11.003.

American Psychiatric Association (2013). Diagnostic and statistical manual of mental disorders (5th edn.). Washington, DC: American Psychiatric Association.

Autism Care Society Nepal. Retrieved March 16, 2017, from https:// autismnepal.org/.

Baird, G., Simonoff, E., Pickles, A., Chandler, S., Loucas, T., Meldrum, D., \& Charman, T. (2006). Prevalence of disorders of the autism spectrum in a population cohort of children in South Thames: The Special Needs and Autism Project (SNAP). Lancet, 368, 210-215. https://doi.org/10.1016/S0140-6736(06)69041-7.

Baron-Cohen, S., Wheelwright, S., Skinner, R., Martin, J., \& Clubley, E. (2001). The autism-spectrum quotient (AQ): Evidence from Asperger syndrome/high-functioning autism, males and females, scientists and mathematicians. Journal of Autism and Developmental Disorders, 31(1), 5-17. Erratum in: J Autism Dev Disord 2001;31(6):603.

Baxter, A. J., Brugha, T. S., Erskine, H. E., Scheurer, R. W., Vos, T., \& Scott, J. G. (2015). The epidemiology and global burden of autism spectrum disorders. Psychological Medicine, 45, 601-613. https ://doi.org/10.1017/s003329171400172x.

Braun, V., \& Clarke, V. (2006). Using thematic analysis in psychology. Qualitative Research in Psychology, 3, 77-101.

Brown, L. D., Cat, T. T., \& DasGupta, A. (2001). Interval estimation for a proportion. Statistical Science, 16, 101-133.

Croen, L. A., Grether, J. K., Hoogstrate, J., \& Selvin, S. (2002). The changing prevalence of autism in California. Journal of Autism and Developmental Disorders 32, 207-215.

Cunningham, K., Ploubidis, G. B., Menon, P., Ruel, M., Kadiyala, S., Uauy, R., \& Ferguson, E. (2015). Women's empowerment in agriculture and child nutritional status in rural Nepal. Public Health Nutrition. https://doi.org/10.1017/S1368980015000683.
Elsabbagh, M., Divan, G., Koh, Y. J., Kim, Y. S., Kauchali, S., Marcín, C. et al. (2012). Global prevalence of autism and other pervasive developmental disorders. Autism Research: Official Journal of the International Society for Autism Research, 5, 160-179. https ://doi.org/10.1002/aur.239.

Fombonne, E. (2009). Epidemiology of pervasive developmental disorders. Pediatric Research, 65, 591-598. https://doi.org/10.1203/ PDR.0b013e31819e7203.

Haworth, E. J., Tumbahangphe, K. M., Costello, A., Manandhar, D., Adhikari, D., Budhathoki, B. et al. (2017). Prenatal and perinatal risk factors for disability in a rural Nepali birth cohort. $B M J$ Global Health. https://doi.org/10.1136/bmjgh-2017-000312.

Heys, M., Alexander, A., Medeiros, E., Tumbahangphe, K. M., Gibbons, F., Shrestha, R. et al. (2016). Understanding parents' and professionals' knowledge and awareness of autism in Nepal. Autism: The International Journal of Research and Practice. https ://doi.org/10.1177/1362361316646558.

Heys, M., Candler, T., Costello, A., Manandhar, D. S., \& Viner, R. M. (2016). Validity of self-reported versus actual age in Nepali children and young people. Public Health, 137, 185-187. https:// doi.org/10.1016/j.puhe.2016.02.014.

Idring, S., Rai, D., Dal, H., Dalman, C., Sturm, H., Zander, E., et al. (2012). Autism spectrum disorders in the Stockholm Youth Cohort: Design, prevalence and validity. PLoS ONE, 7, e41280. https://doi.org/10.1371/journal.pone.0041280.

Kakooza-Mwesige, A., Ssebyala, K., Karamagi, C., Kiguli, S., Smith, K., Anderson, M. C., et al. (2014). Adaptation of the "ten questions" to screen for autism and other neurodevelopmental disorders in Uganda. Autism: The International Journal of Research and Practice 18, 447-457. https://doi.org/10.1177/1362361313475848.

Kenny, L., Hattersley, C., Molins, B., Buckley, C., Povey, C., \& Pellicano, E. (2016). Which terms should be used to describe autism? Perspectives from the UK autism community. Autism: The International Journal of Research and Practice, 20, 442-462. https:// doi.org/10.1177/1362361315588200.

Kim, Y. S., Leventhal, B. L., Koh, Y. J., Fombonne, E., Laska, E., Lim, E. C., et al. (2011). Prevalence of autism spectrum disorders in a total population sample. The American Journal of Psychiatry, 168, 904-912. https://doi.org/10.1176/appi.ajp.2011.10101532.

Kohrt, B. A., \& Harper, I. (2008). Navigating diagnoses: understanding mind-body relations, mental health, and stigma in Nepal. Culture, Medicine and Psychiatry, 32, 462-491. https://doi.org/10.1007/ s11013-008-9110-6.

Kvaal, K., Halding, A. G., \& Kvigne, K. (2014). Social provision and loneliness among older people suffering from chronic physical illness. A mixed-methods approach. Scandinavian Journal of Caring Sciences, 28, 104-111. https://doi.org/10.1111/scs.12041. 
Loomes, R., Hull, L., \& Mandy, W. P. L. (2017). What is the male-tofemale ratio in autism spectrum disorder? A systematic review and meta-analysis. Journal of the American Academy of Child and Adolescent Psychiatry, 56, 466-474. https://doi.org/10.1016/j. jaac.2017.03.013.

Mactaggart, I., Cappa, C., Kuper, H., Loeb, M., \& Polack, S. (2016). Field testing a draft version of the UNICEF/Washington Group Module on child functioning and disability. Background, methodology and preliminary findings from Cameroon and India. ALTER - European Journal of Disability Research/Revue Européenne de Recherche sur le Handicap, 10, 345-360. https://doi. org/10.1016/j.alter.2016.09.003.

Manandhar, D. S., Osrin, D., Shrestha, B. P., Mesko, N., Morrison, J., Tumbahangphe, K. M., et al. (2004). Effect of a participatory intervention with women's groups on birth outcomes in Nepal: Cluster-randomised controlled trial. Lancet, 364, 970-979. https ://doi.org/10.1016/s0140-6736(04)17021-9.

Maulik, P. K., \& Darmstadt, G. L. (2007). Childhood disability in lowand middle-income countries: overview of screening, prevention, services, legislation, and epidemiology. Pediatrics, 120 (Suppl 1), S1-S55. https://doi.org/10.1542/peds.2007-0043B.

Medeiros, E. (2014). Enlightening or frightening? The subjective worlds of the so-called child soldiers of Nepal. University College London.

Mpaka, D. M., Okitundu, D. L. E. A., Ndjukendi, A. O., N'situ, A. M., Kinsala, S. Y., Mukau, J. E., et al. (2016). Prevalence and comorbidities of autism among children referred to the outpatient clinics for neurodevelopmental disorders. The Pan African Medical Journal, 25, 82. https://doi.org/10.11604/pamj.2016.25.82.4151.

Osrin, D., Mesko, N., Shrestha, B. P., Shrestha, D., Tamang, S., Thapa, S., et al. (2003). Implementing a community-based participatory intervention to improve essential newborn care in rural Nepal. Transactions of the Royal Society of Tropical Medicine and Hygiene, 97, 18-21.

Perera, H., Wijewardena, K., \& Aluthwelage, R. (2009). Screening of 18-24-month-old children for autism in a semi-urban community in Sri Lanka. Journal of Tropical Pediatrics, 55, 402-405. https ://doi.org/10.1093/tropej/fmp031.

Petersen, A. C., Crockett, L., Richards, M., \& Boxer, A. (1988). A selfreport measure of pubertal status: Reliability, validity, and initial norms. Journal of Youth and Adolescence, 17, 117-133 https:// doi.org/10.1007/BF01537962.

QSR International Pty Ltd. (2012). NVivo qualitative data analysis software; version 10. Victoria: QSR International Pty Ltd.

Raina, S. K., Chander, V., Bhardwaj, A. K., Kumar, D., Sharma, S., Kashyap, V., et al. (2017). Prevalence of autism spectrum disorder among rural, urban, and tribal children (1-10 years of age). Journal of Neurosciences in Rural Practice, 8, 368-374. https:// doi.org/10.4103/jnrp.jnrp_329_16.
Ren, L., Duan, Z., \& Xu, J. (2003). An analysis on positive of rate autism among preschool children in city. Chinese Journal of Child Care, 2, 105-107.

Ruparelia, K., Abubakar, A., Badoe, E., Bakare, M., Visser, K., Chugani, D. C., et al. (2016). Autism spectrum disorders in Africa: Current challenges in identification, assessment, and treatment: A report on the International child neurology association meeting on ASD in Africa, Ghana, April 3-5, 2014. Journal of Child Neurology, 31, 1018-1026. https://doi.org/10.1177/0883073816635748.

Sinclair, J. (1999). Why I dislike 'person-first' language. Jim Sinclair's website. Retrieved July 5, 2017, from http://www.larry-arnold.net/ Autonomy/index.php/autonomy/article/view/OP1/html_1.

StataCorp. (2015). Stata statistical software: Release 14. College Station, TX: StataCorp LP.

Stewart, L. A., \& Lee, L. C. (2017). Screening for autism spectrum disorder in low- and middle-income countries: A systematic review. Autism: The International Journal of Research and Practice, 21, 527-539. https://doi.org/10.1177/1362361316677025.

Tao, K.-T. (1987). Brief report: Infantile autism in China. China Journal of Autism and Developmental Disorders, 17, 289-296.

UNICEF (2013). State of the world's children: Children with disabilities. New York: UNICEF.

UNICEF (2014). Module on child functioning and disability, Washington, DC: Washington Group on Disability Statistics/UNICEF.

Volkmar, F. R., Szatmari, P., \& Sparrow, S. S. (1993). Sex differences in pervasive developmental disorders. Journal of Autism and Developmental Disorders, 23, 579-591.

Washington Group on Disability Statistics. (2006). Overview of implementation protocols for testing the Washington group short set of questions on disability rationale for and development of the WG questions.

Washington Group on Disability Statistics \& UNICEF. (2014). Module on child functioning and disability.

Washington group on disability statistics understanding and interpreting disability as measured using the WG short set of questions.

Wignyosumarto, S., Mukhlas, M., \& Shirataki, S. (1992). Epidemiological and clinical study of autistic children in Yogyakarta, Indonesia. The Kobe Journal of Medical Sciences, 38, 1-19.

World Bank. (2014). Rural population (\% of total population). Retrieved May 21, 2018, from https://data.worldbank.org/indic ator/SP.RUR.TOTL.ZS.

World Bank. (2016). World Bank Country and Lending Groups. http:// data.worldbank.org/about/country-classifications/country-andlending-groups\#Low_income.

World Health Organisation (2013). Process of translation and adaptation of instruments. World Health Organisation. Retrieved Nov 2, 2017 from http://www.who.int/substance_abuse/research_tools/ translation/en/. 


\section{Affiliations}

Michelle Heys ${ }^{1,2}\left(\right.$ Felicity Gibbons $^{3} \cdot$ Ed Haworth $^{2} \cdot$ Emilie Medeiros $^{1} \cdot$ Kirti Man Tumbahangphe $^{4}$.

Mary Wickenden ${ }^{1} \cdot$ Merina Shrestha ${ }^{5,6} \cdot$ Anthony Costello $^{1,7} \cdot$ Dharma Manandhar $^{4} \cdot$ Elizabeth Pellicano $0^{8,9}$

1 UCL Institute for Global Health, University College London, London, UK

2 Great Ormond Street Institute of Child Global Health, University College London, London, UK

3 Chelsea and Westminster NHS Foundation Trust, London, UK

4 Mother and Infant Research Activities, Kathmandu, Nepal

5 Autism Care Society, Kathmandu, Nepal

6 Tribhuvan University Teaching Hospital, Department of Child Health, Kathmandu, Nepal
7 Department of Maternal, Newborn, Child and Adolescent Health (MCA), World Health Organization, Geneva, Switzerland

8 Centre for Research in Autism and Education (CRAE), UCL Institute of Education, University College London, London, UK

9 Department of Educational Studies, Macquarie University, Sydney, Australia 